\title{
Extraction of Atulic Solution from Atuch and Garlic
}

\author{
Degisew Mihiret Akalat \\ Wollo University, Ethiopia
}

\begin{abstract}
In this thesis paper some general behaviors of plants atuch and garlic was investigated in terms of their selected properties like extractive ability, characterization way, the speed of dying ability and other general physical properties. Generally, the optimum condition of parameters like temperature, selection of solvents, better heating mantles and the like specifications was be focused for better extraction and characterization process. From the solvents hexane and ethanol, hexane was the best extractive agent than ethanol in the way at which time and temperature were investigated during extraction and distillation process. From this activity, the general difference between atuch and garlic was investigated according to their ease of extraction process; therefore eatuch was easily extracted at the same time and temperature and garlic was less extracted at that moment. In the achievement of the laboratory analysis, almost the amount of oil or filtrate also differently investigated in the case of their amount. From the same amount of sample and solvent at the same concerned parameters, the amount of pure filtrate of atuch was $5 \mathrm{ml}$ and that of garlic was $3.9 \mathrm{ml}$.In the color case the filtrate of atuch was yellow and colored and that of garlic was colorless and it is found in the form of white powder. The maximum atuch Leaves oil yield $6.6 \%$ was obtained at extraction time of 3 hours and with solvent ratio $50 \mathrm{ml}$ hexane and $50 \mathrm{ml}$ ethanol. And the minimum atuch leaves oil yield of 3.28\% was obtained at 2 hours and with solvent ratio $50 \mathrm{ml}$ hexane and $50 \mathrm{ml}$ ethanol. The maximum atuch and garlic oil $6.6 \%$ was obtained. when we prepaid atulic solution, we have mixed $75 \%$ atuch solution with $25 \%$ garlic solution at this time it was possible to investigate the gravity difference of the oils.
\end{abstract}

Keywords: atuch; garlic. 